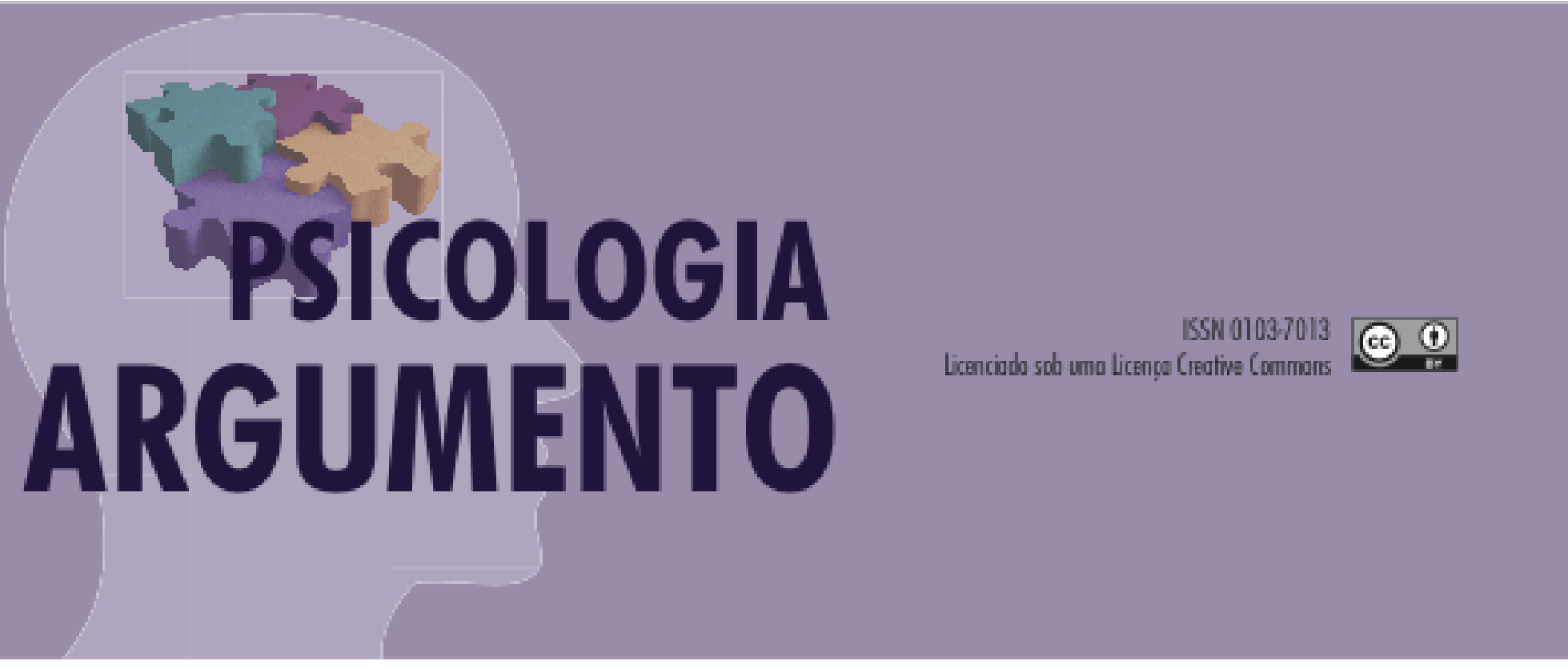

doi: 10.7213/psicol.argum.34.087.A003

\title{
A produção de subjetividade em programas de aprendizagem profissional
}

The production of subjectivity in apprenticeship programs

Daniele Cristina Brock Alves[a], Luciana Albanese $e^{[b]}$

[a] Mestre em Psicologia pela Universidade Federal do Paraná (UFPR), Curitiba, PR - Brasil, e-mail: daniele.brock@gmail.com

[b] Doutora em Psicologia Escolar pela Universidade de São Paulo (USP). Professora Titular do Departamento de Psicologia da Universidade Federal do Paraná (UFPR), Curitiba, PR - Brasil, e-mail: lu5valore@gmail.com

\section{Resumo}

Este artigo objetiva identificar as relações produzidas entre aprendizagem profissional e subjetividade no discurso de jovens aprendizes entrevistados numa entidade formadora do sul do país. O estudo é fruto de uma pesquisa qualitativa baseada no método da Análise Institucional do Discurso, na qual entrevistaramse, individualmente, 10 participantes do Programa Adolescente Aprendiz desenvolvido em tal entidade. Corroborando outras pesquisas, os resultados mostram que as práticas institucionais de um programa de aprendizagem profissional têm implicações nas imagens que os jovens constroem de si, tais como: reconhecerem-se mais responsáveis, maduros, obedientes, autoconfiantes e orientados em relação a um projeto de vida. Constatou-se também que os entrevistados raramente mencionam implicações negativas do programa, aceitando suas práticas como algo necessário para uma vida bem sucedida. Assim, se, por um 
lado, confirma-se a pertinência de tal política pública, por outro, observa-se uma acomodação às exigências do mercado de trabalho e ao "destino" usualmente suposto a estes jovens: de inserção profissional logo após a conclusão do ensino médio.

Palavras-chave: Discurso; políticas públicas; aprendizagem profissional; juventude; subjetividade

\begin{abstract}
This article aims to identify the relationships produced between apprenticeship and subjectivity in the speech of young apprentices interviewed in a training entity of the South of Brazil. The study is the result of a qualitative research based on the method of Institutional Discourse Analysis, in which were individually interviewed 10 participants of Adolescent Apprentice Program, developed in such entity. Corroborating other studies, the results show that institutional practices of an apprenticeship program have implications on the images that young people build about themselves such as: recognize up more responsible, mature, obedient, self-confident and oriented toward a project life. It was also found that respondents rarely mention negative implications of the program, accepting their practices as something necessary for a successful life. Thus, if, on the one hand confirms the relevance of such public policy, on the other, there is the adaptation to the demands of the labor market and the "fate" usually supposed to these young people: entering to the workforce immediately after finishing high school.
\end{abstract}

Keywords: Discourse; public policy; apprenticeship; youth; subjectivity

\title{
Introdução
}

Um grande desafio para a juventude brasileira, principalmente a de camadas populares, é a garantia da própria sobrevivência. Nesta tarefa, a tensão entre a busca de gratificação imediata e um possível projeto de futuro - em que uma carreira possa ser realmente escolhida - faz-se presente. Ao contrário da moratória em relação ao trabalho, realidade de jovens oriundos de classes mais favorecidas economicamente, a juventude de muitos brasileiros é atravessada pela necessidade de trabalhar, de modo a garantir o mínimo de recursos para o lazer, o consumo e a cultura (Sposito, 2005). Com isso, um número cada vez maior de jovens participa de trabalhos ou atividades dos mais diferentes tipos, como forma de ajudar a si próprios e a seus pais na composição da renda familiar. Como consequência, não raro, tem-se o abandono dos estudos e a redução do projeto profissional futuro à perspectiva de inserção laboral em ocupações "escolhidas" conforme as oportunidades encontradas. Em contrapartida, crescem as exigências de qualificação profissional num mercado cada vez mais competitivo e restrito, o que, ao limitar as chances destes jovens a condições laborais geralmente precárias, contribui para sua exclusão social. Diante deste cenário, alguns pesquisadores têm apontado a necessidade de atrelar uma educação de qualidade ao trabalho (Frigotto, 2004), de modo a reduzir, para a juventude em questão, as desigualdades presentes nos processos de inserção e permanência no mundo do trabalho.

Tal fato tem incentivado a criação de inúmeras políticas públicas voltadas à inserção profissional juvenil. Dentre elas, destaca-se a promulgação da Lei da Aprendizagem - Lei 10.097/2000 - e sua regulamentação pelo Decreto 5.598/2005, a qual resultou na criação de programas de aprendizagem profissional com o intuito de desenvolver aptidões para a vida pessoal e profissional de jovens por meio de formação 
teórica e prática. Pela Lei da Aprendizagem, empresas de médio e grande porte devem ter no seu quadro de funcionários uma porcentagem de 5\% a 15\% de aprendizes. Para serem aprendizes, os jovens devem ter entre 14 e 24 anos, estar matriculados no ensino fundamental ou médio e frequentar cursos de formação ministrados por entidades de ensino profissionalizante, ONGs e entidades de assistência social.

A literatura tem apresentado um número crescente de pesquisas envolvendo jovens que estudam e trabalham na condição de aprendizes. Dias, Bulgacov e Camargo (2007), Amazarray, Thomé, Souza, Poletto e Koller (2009), Borges e Coutinho (2010), Mandelli, Soares e Lisboa (2011), Freitas e Oliveira (2012), Macêdo, Alberto e Araujo (2012), Aguilera (2013) e Silva e Trindade (2013) são exemplos desses estudos. Os temas mais recorrentemente explorados por estes pesquisadores consistem em: i) motivações dos jovens para o ingresso em programas de aprendizagem profissional; ii) impactos psicossociais da relação educação e trabalho na vida de jovens aprendizes; iii) mudanças pessoais percebidas pelos jovens com a experiência de ser aprendiz; iv) expectativas de futuro, educação para a carreira e construção de projetos de vida para aprendizes; v) vivência subjetiva do desemprego após o término do contrato de aprendiz.

A Lei da Aprendizagem assegura ao aprendiz formação técnico-profissional metódica, compatível com o seu desenvolvimento físico, moral e psicológico. Esta formação caracteriza-se por atividades teóricas e práticas, pedagogicamente articuladas entre si, organizadas em tarefas de complexidade progressiva sob a forma de itinerários formativos (Brasil, 2000).

O Decreto n. 5.528/2005 acrescenta que a formação técnico-profissional metódica para aprendizes deverá realizar-se por meio de programas de aprendizagem profissional, organizados e desenvolvidos sob a responsabilidade e orientação de entidades qualificadas neste tipo de formação (Brasil, 2005). No artigo $7^{\circ}$ deste Decreto, constam os princípios que a formação do aprendiz deve obedecer, a saber: "I - garantia de acesso e frequência obrigatória ao ensino fundamental; II - horário especial para o exercício das atividades; e III - capacitação profissional adequada ao mercado de trabalho" (Brasil, 2005).

Os programas de aprendizagem devem se adequar às diretrizes curriculares nacionais e às normas federais relativas à formação inicial e continuada de trabalhadores. As entidades formadoras precisam contemplar em seus cursos, conteúdos e habilidades requeridas para o desempenho das ocupações objeto da aprendizagem, que se encontram descritas na Classificação Brasileira de Ocupações (CBO). Neste documento constam: o nome das ocupações, a faixa etária de quem pode exercê-las, a carga horária de atividades práticas e teóricas a serem desenvolvidas e a descrição das atividades a serem desempenhadas (Brasil, 2012).

Os programas de aprendizagem profissional constituem uma forma de inserção laboral do jovem, que visam proporcionar o desenvolvimento da cidadania, a compreensão das características do mundo do trabalho, dos fundamentos técnico-científicos e das atividades técnico-tecnológicas específicas à ocupação (Brasil, 2012). Para isso, os jovens frequentam carga horária de atividades práticas em uma empresa e teóricas em uma entidade formadora.

Para fins deste estudo, buscaram-se pesquisas que tratam de aspectos subjetivos envolvidos na inserção laboral juvenil. Em sua análise sobre trabalho e estudos na vida de jovens de camadas populares Raitz e Petters (2008), por exemplo, constataram a importância do trabalho para a busca pela emancipação, autonomia e direitos iguais aos dos 
jovens de camadas médias e altas. Para os jovens, por elas pesquisados, a educação é considerada o meio pelo qual conquistarão seu futuro profissional e terão melhor compreensão da realidade. As autoras verificaram, entretanto, que os conhecimentos adquiridos na escola nem sempre tem aplicabilidade no trabalho do jovem e vice-versa. Ainda quanto à relação trabalho e estudos nesta população, Oliveira, Sá, Fisher, Martins e Teixeira (2001) reportaram que os jovens a associam ao cansaço e à sobrecarga física: a falta de tempo para estudar, descansar e praticar atividades de lazer acaba resultando em falta de interesse na escola, dificuldade em aprender e altos níveis de estresse.

No que diz respeito ao trabalho, todavia, e em que pese o fato de estar submetido ao controle que os superiores exercem sobre suas atividades laborais, o jovem aprendiz conquista mais autonomia e, consequentemente, maior liberdade diante da autoridade dos pais ou responsáveis (Guimarães \& Romanelli, 2002). Isso se relaciona ao que Oliveira e Robazzi (2001) encontraram em sua pesquisa. Elas observaram que o trabalho é considerado pelos jovens como um rito de passagem para a vida adulta, que possibilita a percepção de si como adulto e importante, capaz de produzir e de ter autonomia financeira em relação aos seus pais. As autoras chamam a este processo de adultização, pois o jovem passa a assumir papéis sociais destinados ao adulto tornando-se, muitas vezes, o provedor da renda familiar. Segundo elas, se a situação de adultização não é acompanhada por um processo de amadurecimento psicológico, por um lado, pode trazer prejuízos afetivos e intelectuais ao jovem. Por outro lado, o trabalho pode ser estruturante da identidade se puder proporcionar ao jovem um sentido de vida, facilitando suas escolhas profissionais à medida que venha a constituir uma fonte de informações e aprendizagem, além de permitir novos contatos sociais (Sarriera, Silva, Kabbas \& Lópes, 2001). Os autores constataram que, para jovens de classes populares, a inserção no mundo do trabalho representava a possibilidade de transformação de sua realidade social para uma perspectiva melhor de futuro.

Quanto à inserção laboral de jovens aprendizes, público alvo do presente estudo, Dias et.al. (2007) observaram que os mesmos relacionavam o contexto da aprendizagem à possibilidade de construírem novos modos de ser e outros planos para o futuro. Segundo as autoras, estar em um programa de aprendizagem gerava nos jovens expectativas e sonhos, como por exemplo, projetos de carreira em grandes empresas. Quando o contrato de aprendizagem se encerrava, no entanto, o cenário mudava. Os jovens passavam subitamente à condição de desempregados e, muitas vezes, precisavam suspender ou mudar seus planos.

Para Amazarray et.al (2009) os jovens aprendizes compreendem o "ser trabalhador" e o "ser aprendiz" como experiências semelhantes, pois nelas consideram realizar praticamente as mesmas atividades. Ao mesmo tempo são experiências diferentes, pois percebem que o nível de cobrança do aprendiz é menor. A mencionada pesquisa demonstrou que, ao se referirem ao futuro profissional, jovens aprendizes manifestavam interesse em continuar trabalhando na empresa onde estavam contratados, no entanto, apresentavam certa indefinição em relação à escolha profissional. Da mesma forma, jovens aprendizes pesquisados por Borges e Coutinho (2010) apresentavam dúvidas quanto às escolhas profissionais e/ou dúvidas em sua trajetória futura, realizando escolhas e projetos sem a possibilidade de participarem de programas de orientação profissional.

Macêdo et. al. (2012), ao estudarem as expectativas de futuro de jovens aprendizes, concluem que os dispositivos institucionais de um programa de aprendizagem profissional 
e da sociedade capitalista como um todo, de certa forma, fabricam, modelam, adestram o sujeito para o mundo do trabalho. Inseridos nesse contexto, alguns jovens não conseguem compreender que seus planos para o futuro estão relacionados ao mundo social em que vivem, e assim, colocam seus sonhos num lugar idealizado, sem se questionarem sobre sua viabilidade. Outros jovens, entretanto, vislumbram um futuro mais pautado na realidade, buscando formas de superar as adversidades do meio social para realizarem seus sonhos.

Dentre as pesquisas consultadas a de Silva e Trindade (2013) é a que mais se aproxima do objetivo do presente estudo. As autoras investigaram mudanças pessoais observadas por jovens recém-ingressos em um programa de aprendizagem. Constataram que, tanto meninas como meninos, confirmaram impactos positivos do programa em seu autoconceito. As principais modificações apresentadas pelos aprendizes foram: crescimento profissional, aquisição de habilidades sociais e independência.

Uma vez que o interesse deste artigo é tratar da produção de subjetividade em programas de aprendizagem profissional, torna-se importante ressaltar, que estudos contemporâneos sobre a subjetividade não estão mais circunscritos às concepções clássicas de sujeito, ou seja, a tradições teóricas que o compreendem como fundamento, substância, centro, essência de todas as coisas. O início deste século trouxe o entendimento da subjetividade como sendo, ao mesmo tempo, produzida por e (re) produtora de relações históricas, sociais e simbólicas, ou seja, como produto de processos políticos, econômicos, científicos, tecnológicos, artísticos, etc., datados e situados em uma trama complexa (Pan, Rossler, Ferrarini, Valore \& Oliveira, 2011).

A Análise Institucional do Discurso (AID) compartilha desta ideia. Entende "sujeito" como suporte do discurso institucional. Ao mesmo tempo, esse discurso será suporte de sua condição de sujeito. Trata-se, portanto, de uma relação constitutiva entre discursoinstituição-sujeito, em que uma instância não pode ser pensada exteriormente à outra. A condição de efeito de discursos, no entanto, não anula a possibilidade de singularidade ao se conceber um sujeito-posição, ou seja, alguém que irá marcar posição em seu dizer, organizando a seu modo e de acordo com a sua história particular, sentidos, estilos de pensar, perceber e falar. Influenciada pelas ideias de Foucault, a AID compreende a "subjetividade" como produto das relações de poder, isto é, da tensão estabelecida entre sujeição e resistência do sujeito às práticas sociais instituídas, à ordem do discurso (Pan et al, 2011). Discurso aqui pensado para além de sua função representacional da realidade, posto que configura a própria realidade: discurso ato que produz verdades, instituições e lugares subjetivos (Foucault, 1971).

Para Guirado (1997) a subjetividade é matriciada no conjunto das relações institucionais, não excluindo a questão da singularidade psíquica. Deve ser entendida enquanto organizações particulares de uma história de relações e de vínculos. Assim, por exemplo, quando um jovem fala de si, do programa de aprendizagem que frequenta, da empresa na qual trabalha, das pessoas que lá estão, dos seus estudos enfim, ele o faz num dizer que ao mesmo tempo em que deixa entrever suas condições institucionais de produção (instituição aqui entendida como conjunto de práticas sociais e de saberes que se repetem e, deste modo legitimam-se), permite reconhecer uma marca singular (no modo com que se apropria, recusa, naturaliza, subverte as verdades institucionalmente legitimadas). E será nesse movimento de assujeitamento e resistência no discurso que um sujeito-posição (ou modos de subjetivação) irá se produzir. 
Guirado propõe, então, que o âmbito daquilo que se costuma entender como psíquico seja concebido como efeito institucional; isto é, como efeito de reconhecimentos da naturalidade e de desconhecimentos da relatividade dos lugares institucionais-discursivos que se ocupam e se reeditam em uma história de vida. Ao constituir-se em meio a relações e vínculos afetivos institucionalizados (como a família, a escola, o trabalho, por exemplo), o sujeito se organiza e é organizado pelas instituições, não podendo existir fora delas, nem elas sem a ação dele (Guirado, 2009). Assim, a subjetividade deve ser considerada como produto de um processo e não, como algo inerente, dado de saída e que acompanha o indivíduo em suas contínuas interações (delas recebendo múltiplas influências).

Entender o sujeito, portanto, como efeito do imbricamento das marcas históricas de cada um e do contexto institucional presente, permite pensar que sempre haverá maneiras singulares de se fazer as instituições e as subjetividades. O jovem, mesmo assujeitado à ordem do discurso das práticas institucionais contemporâneas, terá sua forma singular de organizar sentidos, de se movimentar nas relações de poder, compondo sua condição de sujeito psíquico e produzindo e reproduzindo as instituições em que vive.

O presente artigo resulta de uma pesquisa com jovens participantes de um programa de aprendizagem profissional e tem como foco o aspecto das mudanças pessoais percebidas em tal experiência. Embora tal tema já tenha sido objeto de investigação, a abordagem aqui proposta ainda tem sido pouco explorada, o que possibilita vislumbrar alguma contribuição ao conjunto dos demais estudos realizados. Seu principal objetivo é delinear, no discurso dos participantes da pesquisa, as relações estabelecidas entre a experiência de aprendizagem profissional e as imagens de si. Tal objetivo configurou-se tendo em vista a perspectiva metodológica adotada - a Análise Institucional do Discurso (AID) (Guirado, 2010) - segundo a qual a produção de subjetividade (que aqui nomeamos de "imagens de si”) se dá nas práticas institucionais discursivas. Dito de outro modo, nessa perspectiva, o reconhecimento de um si como sujeito se dá, sempre, no discurso. Adiante serão retomados os conceitos que dão sustentação a esta proposta que, segundo sua autora, configura-se como uma "analítica da subjetividade" (Guirado, 2010). Por ora, sinaliza-se a expectativa de que, não obstante a limitação da amostra de pesquisa, o presente artigo possa contribuir na investigação do papel das práticas educativas (no caso, as desenvolvidas no âmbito de programas de aprendizagem profissional) na produção de subjetividades, bem como nas reflexões concernentes aos desafios ainda presentes no aprimoramento e consolidação destes programas como efetivas estratégias de enfrentamento aos processos de exclusão que assombram, de maneira crescente, boa parte da juventude brasileira.

\section{Método}

\section{Participantes}

Participaram desta pesquisa, 10 jovens, sendo 5 moças e 5 rapazes, de idades entre 16 e 18 anos, residentes em Curitiba e participantes do Programa Adolescente Aprendiz, há no mínimo, um ano e meio. O tempo de inserção no programa, a intenção de abranger igual número de representantes de cada sexo e o fato de não terem tido contato próximo com a pesquisadora (que atuava como psicóloga no referido programa) previamente à 
pesquisa foram os únicos critérios adotados para a seleção da amostra. Em sua maioria, os jovens participantes eram provenientes de famílias assistidas pelos Centros de Referência da Assistência Social (CRASs). Todos eles estudavam ou tinham estudado em escolas públicas, sendo que 5 deles cursavam o terceiro ano do ensino médio e outros 5 tinham o ensino médio completo. O programa de aprendizagem que freqüentavam, os qualificava nas áreas de serviços administrativos e bancários. Cumpriam carga horária de atividades práticas em empresas diversas e de atividades teóricas, em uma entidade formadora de aprendizes.

\section{Instrumento}

A proposta de investigação foi aprovada pelo Comitê de Ética em Pesquisa da Universidade à qual os pesquisadores estavam vinculados. $\mathrm{O}$ instrumento de pesquisa consistiu em uma entrevista semiestruturada, cujo roteiro foi especialmente elaborado para os fins do estudo. Os participantes foram convidados para as entrevistas, após a explicação dos objetivos do estudo e a informação concernente ao sigilo de sua identidade. Os jovens que se voluntariaram assinaram o Termo de Consentimento, o mesmo tendo sido feito por seus responsáveis, no caso de os entrevistados serem menores de idade (para estes foi solicitada a assinatura de um Termo de Assentimento). Com as devidas autorizações, as entrevistas foram gravadas, transcritas e posteriormente analisadas pela equipe de pesquisadores.

Em consonância com o referencial da Análise Institucional do Discurso (AID) não se pretendeu realizar uma análise quantitativa, nem um tratamento estatístico dos dados que resultasse em generalizações. Dessa forma, a análise das entrevistas focou a identificação das regularidades discursivas (dizeres recorrentes), das naturalizações operadas, do interdiscurso (múltiplas vozes presentes nas falas) e dos efeitos de desconhecimento das condições institucionais de produção do discurso. Numa perspectiva em que, mais do que se atentar ao conteúdo do que é dito, observa-se o modo com que se diz, buscou-se relacionar o texto ao contexto das falas, investigando as verdades nelas legitimadas e os modos de subjetivação configurados - e nestes, a singularidade no dizer. Em momento posterior confrontaram-se as análises às realizadas em outras pesquisas.

Para efeitos da apresentação dos resultados neste artigo, selecionaram-se os extratos discursivos e/ou as expressões mais exemplarmente relacionadas às imagens de si que puderam ser reconhecidas pelos entrevistados como efeito de sua participação no programa de aprendizagem profissional. Em geral, tais extratos foram retirados das respostas referentes às perguntas "Você percebeu mudanças em sua vida após o ingresso no Programa de Aprendizagem? Dê exemplos" e "Em você, percebeu mudanças ou alguma pessoa próxima comentou algo a respeito?". Além disto, outros trechos dos depoimentos em que as relações entre a participação no programa e a produção de subjetividade puderam ser evidenciadas também foram utilizados, uma vez que, muitas vezes, ao falarem do programa também mostravam expectativas ou outros atributos referentes a imagens de si.

No item a seguir serão apresentados os principais resultados da pesquisa sobre a produção de subjetividade em programas de aprendizagem, os quais puderam ser agrupados em dois grandes eixos discursivos, a saber: a produção de subjetividade nas práticas da entidade formadora e a produção de subjetividade nas práticas da empresa contratante. Tal divisão visa a explicitar as diferenças evidenciadas nos modos de subjetivação num con- 
texto e no outro. Vale registrar que as expressões colocadas entre aspas e em itálico foram extraídas dos depoimentos dos entrevistados.

\section{Resultados}

\section{Subjetividade nas práticas da entidade formadora}

Ao enunciar as expectativas relacionadas ao ingresso no programa de aprendizagem, o discurso dos entrevistados corroborou a naturalização do encaminhamento socialmente esperado para jovens pertencentes às camadas populares: a inserção imediata no mercado de trabalho como estratégia para a obtenção da independência financeira ou, pelo menos, para o incremento da renda familiar. Curiosamente, a notícia de que teriam que fazer um curso de qualificação em uma entidade formadora a fim de obter uma colocação, foi legitimada como atraso ou empecilho aos seus planos. Ao falar de sua inserção no programa, um dos entrevistados relatou: "Eu falei: ah, um curso de profissionalização... eles falaram que eu tinha que fazer dois meses antes... aí eu falei: achei que já ia direto, eu achava que não ia demorar tanto!".

Paralelamente ao desapontamento quanto à não obtenção imediata de emprego, o sentimento de desconfiança em relação ao programa de aprendizagem mostrou-se uma regularidade nos discursos dos entrevistados. Um dos jovens reconheceu ter chegado ao programa "não acreditando muito", "meio avoado"; já outro referiu ter ficado "animado, mas "indeciso", "contente e ao mesmo tempo receoso". Segundo este último, já tinha ido a vários lugares cuja promessa era "dar emprego", mas "acabou não dando em nada". $\mathrm{O}$ fato de ter se frustrado com o discurso de algumas instituições, talvez tenha produzido uma imagem de que não eram confiáveis, constituindo sua posição de indecisão e receio ao ingressar no programa. Tais discursos confirmam o sentido a ele atribuído de oportunidade de inserção no mercado de trabalho.

Os jovens foram questionados sobre as contribuições que reconheciam da entidade formadora para suas vidas, uma vez que já estavam no programa de aprendizagem há mais de um ano e meio. Todos os entrevistados atribuíram ganhos pessoais à experiência no programa, os quais foram associados tanto ao âmbito escolar (melhorias no rendimento acadêmico, justificado pela responsabilidade adquirida no trabalho), quanto ao do contexto laboral. Neste, as "aquisições" mais recorrentemente afirmadas foram: a superação da timidez, o uso da linguagem formal, o aprendizado quanto à vestimenta adequada para o local de trabalho, a aceitação de regras e, sobretudo, o desenvolvimento da responsabilidade. O extrato abaixo é emblemático:

Me ajudou também a criar responsabilidade, muita responsabilidade. Quando eu fui pra empresa eu pensei: pô vou com a minha mãe fazer entrevista, coisa de menor, né? Daí eu pensei: vou ir junto com a minha mãe, mas, não. Vocês queriam dar responsabilidade pra gente, pra gente chegar lá e com as nossas palavras falar as coisas.

Segundo uma das jovens: "O (nome da entidade formadora), pelas regras que ele tem, ele te faz viver de uma maneira diferente. Faz você seguir uma norma, você acaba se acostumando e levando estas normas pra todo lugar que você vá". Assim, embora resistente à imposição normativa ("você acaba se acostumando"), a entrevistada subjetiva-se, na cena da entrevista, como obediente aprendiz. Pode-se considerar que tal apelo - da obediência como requisito para o sucesso- ganhe força por estar articulado a outros discur- 
sos socialmente instituídos, em especial, os que configuram as práticas educativas familiares e escolares. Além disto, outro aspecto a ser observado refere-se à interlocutora privilegiada nesta fala: a entrevistadora psicóloga da entidade em questão.

Entretanto, como nem tudo é assujeitamento nas relações discursivas, em alguns depoimentos as expressões "rígido demais" e "muito rígido" foram empregadas ao se referirem à intensidade como as regras são impostas pela entidade formadora. A rigidez em relação ao controle da vestimenta e das faltas que podem apresentar no curso profissionalizante foi questionada por alguns entrevistados.

Outro aspecto analisado, parte do seguinte trecho: “(...) é cansativo sair do trabalho e vim pra cá, mas eu não vejo outro jeito (...)”. Neste enunciado o jovem deixa implícita a insatisfação: além de estudar e trabalhar, frequentar a entidade formadora, para o curso profissionalizante. Todavia, parece que se conforma diante das circunstâncias. Estes, não obstante mostrem, implicitamente, em seus discursos a visualização de possibilidades para ser "de outro jeito", parecem não encontrar palavras para poderem dizê-lo. Resta, portanto, o assujeitamento à impossibilidade - reconhecida como pessoal ("mas eu não") de "ver outro jeito".

Em síntese, a imagem que os jovens entrevistados constituem da entidade formadora é de facilitadora da inserção no mercado de trabalho e isto porque, ainda que assumam a importância dos conteúdos teóricos ensinados, "aprendem mais na parte prática". Tal aprendizado, como visto, reside, basicamente, na regulação de seus discursos e comportamentos, a qual os prepara para as exigências do mundo corporativo. Nas relações com o discurso da instituição formadora subjetivam-se, enfim, como efetivos aprendizes.

\section{Subjetividade nas práticas da empresa contratante}

No discurso dos jovens entrevistados, o termo "programa de aprendizagem profissional" aparece mais relacionado ao trabalho, ou seja, às atividades práticas que realizam na empresa contratante, do que às atividades teóricas realizadas na entidade formadora. Ao falar do que mais gostava no programa de aprendizagem uma das jovens diz: "eu gosto de trabalhar, gosto de tá lá, assim, das amizades que eu tenho, do que eu faço, do que eu trabalho, eu gosto".

Em comparação à escola e à entidade formadora, os aprendizes parecem atribuir à instituição onde trabalham a necessidade de maior seriedade e respeito. Efetivamente, ao falarem de sua vida na escola, a maioria dos jovens desenhou um cenário caracterizado por "menor seriedade", "brincadeira" e "menor responsabilidade" do que o instituído pelas práticas exercidas no programa de aprendizagem. Os seguintes extratos ajudam a exemplificar este argumento:

"Na escola não tem, tem um limite também, mas é um limite mais expandido digamos assim. Você brinca com os professores, os professores brincam com você. Na empresa é mais profissional. Você tem até aquelas brincadeiras, mas você não pode passar de um certo limite. Tem um limite."

No discurso de outro jovem: "Bom, o colégio... eu acho que no terceiro ano eu levei muito na brincadeira (... e daí na empresa, já é uma coisa mais séria, você tem que respeitar as ordens, as regras da empresa".

Nota-se também, que ao falarem da empresa, os aprendizes logo a relacionam às pessoas do trabalho, das quais dizem: "estão sempre pedindo para fazer coisas diferentes", são "gente boa" e "estão dispostas a ajudar". Tais dizeres indicam que o lugar de 
aprendiz vai se constituindo nas práticas do trabalho e na convivência com outros trabalhadores.

Observa-se no discurso dos jovens, que há, por parte das instituições onde trabalham, o reconhecimento da singularidade da condição de aprendiz, o que lhes confere um lugar diferenciado. Um dos jovens exemplifica isso ao dizer da posição que ocupa entre os funcionários da empresa. Ele diz: "Eu sou o bebê. Me chamam de bebê lâ". Neste caso, pode-se pensar na reedição de lugares existente nas relações institucionais, que faz com que os aprendizes repitam no trabalho a posição subjetiva que, muitas vezes, ocupam na família.

Os entrevistados se referem à inserção nas empresas como possibilidade de se depararem com uma realidade diferente da qual estavam acostumados e de fazer coisas que nunca haviam feito. Apesar de enunciarem a vida de aprendiz como "desafiadora", "complicada", "corrida", "difícil", os jovens também dizem que é "boa, não tem que trabalhar tanto".

"Sou mais responsável", "fiquei mais responsável", "já tenho minha responsabilidade" foram expressões que apareceram repetidas vezes no discurso dos aprendizes, indicando a aquisição de responsabilidade como uma das principais mudanças após a entrada no programa. Organização em relação aos horários, às prioridades e mudanças na maneira de pensar também foram mencionadas pelos aprendizes. Em seus dizeres, se reconhecem mais autoconfiantes, independentes, capazes de aprender, lutadores, persistentes, adaptáveis aos desafios e privilegiados em relação a outros jovens.

Os entrevistados apontaram novos modos de ser em relação ao colégio após a inserção no programa de aprendizagem. Para exemplificar isso, destacam-se os seguintes trechos:

(...) não ligava tanto com o tempo... o pessoal da escola me conhecia, porque eu chegava sempre atrasado lá, não tava nem aí. Já na empresa não poderia acontecer isso. Lá descontava e depois sente no bolso. Porque só aprende assim mesmo. Eu acabei tendo uma rigidez maior com o tempo. Depois disso, até na escola eu não tive mais problema de chegar atrasado.

(...) me deu mais responsabilidade. Até queria desistir uma vez do colégio, mas por causa do aprendiz, não desisti.

$\mathrm{O}$ primeiro extrato sugere que ser pontual foi uma responsabilidade adquirida por exigência do trabalho, que se estendeu também para o colégio. No enunciado: "Porque só aprende assim mesmo" o jovem apresenta um discurso naturalizado, ao mesmo tempo em que legitima a ideia de que o aprendizado só se dá quando há uma perda, no caso dele, financeira. No segundo extrato, uma das jovens indica que as exigências do programa deram um novo sentido para que continuasse estudando. A aprendiz parece ciente de que se não frequentasse o colégio, poderia perder a oportunidade de estar no programa.

$\mathrm{O}$ "amadurecimento" também aparece com frequência no discurso dos jovens, relacionado às práticas do programa de aprendizagem. $\mathrm{O}$ aprendiz se percebe um jovem mais sério, maduro, que pensa e age como adulto. Na fala de um dos jovens isso ficou mais claro: "Falam que eu cresci um pouco. Que eu fiquei mais adulto. Eu era meio crianção... agora continuo sendo, mas agora tô mais adulto. A mentalidade muda um pouco".

Mesmo se não fossem aprendizes, os jovens sugerem que estariam em busca de realizar seus projetos de vida. Nota-se, entretanto, que o programa de aprendizagem tem um lugar de orientação, apoio, aquisição de conhecimentos e facilitação para a concretização 
de seus planos. Pode-se analisar isso em enunciados tais como: "Acho que se não fosse um aprendiz, meu futuro seria meio que desorientado", "eu estaria do mesmo jeito tentando a faculdade, mas só que sem esse apoio", "eu ia acabar trabalhando em qualquer lugar, sem aprender, trabalhar só por trabalhar, conseguir dinheiro".

Alguns dos jovens entrevistados reconhecem contribuições mais diretas da empresa contratante em seus projetos de vida. Uma das jovens diz: "até então eu nunca tinha visto administração e daí administração eu vi, acabei gostando e é uma coisa que agora eu quero fazer: ou administração ou contabilidade". Em outros enunciados, os aprendizes parecem não encontrar uma relação direta do programa com a área que querem seguir, mas reconhecem contribuições indiretas do mesmo: "Eu acho que de uma certa forma ajudou", "Não ajudou, mas apoiou".

Observa-se que, as práticas da instituição contratante não são questionadas pelos aprendizes, que parecem reconhecer em tudo o que fazem e naquilo que lhes ensinam consequências positivas para o presente e para o futuro.

\section{Discussões}

Discursos anteriores à inserção no programa de aprendizagem constituem expectativas e fazem diferença nos sentidos a ele atribuídos. Chama atenção a naturalização de que exercer uma ocupação não requer qualificação e isto, ainda que não explicitado por ocasião das respostas à pergunta sobre as expectativas quanto ao programa, associado a outros trechos em que discorreram sobre a escola, sugere que práticas de formação "de verdade" só acontecem no contexto do trabalho. Assim, em que pese a importância atribuída à escolarização, sua valorização parece consistir, essencialmente, no fornecimento de um diploma.

Quanto às contribuições da entidade formadora, verificam-se implicações subjetivas de tais práticas institucionais, pois, a partir delas o jovem subjetiva-se como ser mais autônomo. Ao mesmo tempo, porém, evidencia-se um desconhecimento da relatividade dessa autonomia, pois para poder se manter nesse lugar, terá que assujeitar-se às regras da empresa, adequar sua vestimenta, seu vocabulário e conduta.

De "menor" o aprendiz passa a se perceber como "maior", atribuindo à entidade formadora o incentivo para uma espécie de rito de passagem, o qual lhe permite superar a condição de dependência do mundo familiar rumo a uma condição de suposta independência no mundo do trabalho. A entidade formadora parece operar como reguladora de comportamentos para a transição para essa maioridade. A sujeição começa a ser praticada e naturalizada antes mesmo do ingresso nas empresas. Isto pode ser evidenciado no discurso dos aprendizes ao atribuírem ao programa o lugar de estabelecimento (e cumprimento) de regras, normas, limites e de aprendizado, sobretudo, no âmbito comportamental. Interessante observar que, conquanto seja uma instituição responsável por ministrar os cursos teóricos do programa, esta formação parece ficar em segundo plano no discurso dos aprendizes.

A transição para vida adulta, ao que parece no discurso dos jovens não se dá sem tensão: a resistência em abrir mão das marcas do que os identifica ao seu grupo de pares (como o uso do boné, por exemplo) para se enquadrar às marcas do mundo corporativo, mesmo tendo sido vencida nas práticas dos aprendizes, continua a se fazer valer no discurso produzido para a entrevistadora, representante do programa. 
Em seus estudos, Oliveira e Robazzi (2001) observaram que atividades de geração de renda para jovens, ofertadas na forma de programas ou por meio das entidades mediadoras costumam exigir disciplina e controle do jovem. Segundo as autoras, mantendo-se o jovem dócil, obediente, disposto para o trabalho, mantém-se a relação de dominação / subordinação implícita no discurso do modelo social vigente, perpetuando-o.

Ribeiro (2011), em sua pesquisa com jovens trabalhadores, encontra discursos que se aproximam aos encontrados nesta pesquisa. Ele observou que a reivindicação por direitos não apareceu como a dimensão mais importante do trabalho, fazendo transparecer uma naturalização da situação dada e a tentativa dos jovens de extrair desta realidade o que ela teria de melhor. $\mathrm{O}$ autor argumenta que para os jovens que vivem em situação de vulnerabilidade social a sobrevivência é mais premente do que a tentativa de mudança. Seus discursos, portanto, seguem mais no sentido do "o que fazer" no mundo que está dado do que no "o que fazer" para mudar este mundo. Com isso, pode-se dizer que a atual configuração do mundo do trabalho, cuja lógica é perpetuada e incentivada nas práticas educativas, parece impor certas exigências que passam a ser naturalizadas e legitimadas pela sociedade e consequentemente pelos jovens.

Quando analisados os dados referentes à subjetividade produzida nas práticas das empresas contratantes, os aprendizes sugerem em seus discursos que o contrato de aprendizagem profissional lhes oferece algumas vantagens em comparação a outros jovens. Tais achados corroboram a pesquisa de Amazarray et.al (2009) na qual os jovens relataram que ser aprendiz é um privilégio de inserção no mercado de trabalho em relação a outros jovens e uma experiência importante para o futuro.

Os jovens sinalizam em suas falas que o envolvimento com o aprendizado está relacionado às consequências, as quais talvez não consigam reconhecer nas práticas do colégio. Interessante observar que autores como Pochmann (2007) criticam a relação trabalhoestudos dentro do grupo juvenil. Para ele, a entrada precoce no mercado de trabalho impede a formação teórica adequada. Defende o autor, que somente com a postergação nas inserções laborais, os jovens poderiam ampliar seus requisitos educacionais e atender aos desafios da sociedade do conhecimento. Dados levantados pela presente pesquisa e pelos estudos de Borges e Coutinho (2011), entretanto, apontam que no discurso de jovens aprendizes, predominam as positividades de tal condição. Valorização dos estudos, ganho de independência, responsabilidade e ocupação do tempo livre de maneira boa, são discursos encontrados nesta e em outras pesquisas com este público.

Assim como identificado neste estudo, a responsabilidade e o amadurecimento apareceram como aquisições dos jovens nas práticas do programa de aprendizagem, especialmente na relação com a empresa. No estudo de Silva e Trindade (2013) os aprendizes também apontam mudanças relacionadas à inserção no trabalho como a responsabilidade e características que se aproximam do mundo adulto como amadurecimento e perspectiva de futuro.

Pôde-se perceber o reconhecimento dos jovens de contribuições diretas da empresa para suas vidas presentes e futuras. Amazarray et.al (2009) observaram que há certa idealização do jovem em relação à empresa, em virtude do ambiente de trabalho agradável, possibilidades de aprendizado, acolhimento e por ser a primeira experiência profissional. Esse contexto pode produzir expectativas de permanecer na empresa como efetivo, bem como implicações nas suas escolhas profissionais. 


\section{Considerações finais}

Dentre as inúmeras análises possíveis, a que se fez é um recorte, que tenta responder ao objetivo deste artigo. Pode-se dizer, que tanto as práticas da entidade formadora, quanto às da empresa contratante estão relacionadas, no discurso dos aprendizes, a um novo modo de ser: um jovem que se reconhece adulto e trabalhador, ou seja, mais sério, maduro, responsável, obediente às regras e com projetos para o futuro. Tais imagens de si são consideradas positivas pelos jovens, pois vão ao encontro do que é considerado positivo pelo discurso do atual mundo corporativo, do qual fazem parte.

A experiência do programa de aprendizagem é reconhecida pelos jovens como oportunidade de mudança de vida, que por sua vez, está relacionada a mudanças em si mesmos. Seus discursos corroboram o pressuposto neoliberal de que o maior ou menor sucesso depende exclusivamente do esforço pessoal. Os entrevistados consideram a condição de aprendiz um passo à frente de outros jovens e se sentem privilegiados por isso. Implicações negativas quase não são mencionadas, o que leva a pensar, por um lado, em discursos produzidos para a entrevistadora, que atua em um programa de aprendizagem e, por outro, podem indicar que, o que há de negativo é naturalizado pelos jovens como parte da vida daqueles que querem um futuro melhor.

Considera-se, portanto, que a inclusão de jovens no mundo do trabalho por meio da Lei da Aprendizagem atende aos interesses do mundo capitalista, produzindo sujeitos que se enquadrem aos seus objetivos e, ao mesmo tempo, atende aos interesses de jovens de camadas populares, indo ao encontro de suas expectativas. Assim, se, por um lado, confirma-se a pertinência de tal política pública, por outro, observa-se um assujeitamento às exigências do mercado de trabalho e ao "destino" usualmente suposto a estes jovens: de inserção laboral profissional logo após a conclusão do ensino médio.

Para que a Lei da Aprendizagem possa constituir-se em uma prática educativa de promoção de autonomia e cidadania dos jovens julga-se importante, ações que venham a promover, junto aos aprendizes, a reflexão crítica sobre temas como: a sociedade contemporânea, consumo, relações de trabalho, qualificação profissional e outros temas do cotidiano, de modo que, ao mesmo tempo em que se reconheçam efeitos de discursos já existentes, possam também vir a se reconhecer como produtores de novos discursos.

\section{Referências}

Aguillera, F. (2013). Projeto de vida e preparação para a carreira de jovens aprendizes: da realidade à intervenção. Dissertação de Doutorado, Programa de Pós-Graduação em Psicologia, Universidade de São Paulo, São Paulo.

Amazarray, M. R., Thomé, L. D., Souza, A. P. P., Poletto, M., \& Koller, S. H. (2009). Aprendiz versus trabalhador: adolescentes em processo de aprendizagem. Psicologia: Teoria e Pesquisa, 25(3), 329-338.

Borges, R. C. P., \& Coutinho, M. C. (2010). Trajetórias juvenis: Primeiro emprego e projetos de vida. Revista Brasileira de Orientação Profissional, 11(2), 189-200. 
Decreto no 5.598, de 01 dezembro de 2005 (2005, 02 de dezembro). Regulamenta a contratação de aprendizes e dá outras providências. Brasília, DF: Presidência da República: Casa Civil. Subchefia para Assuntos Jurídicos. Recuperado em 22, novembro, 2015, de http://www.planalto.gov.br/ccivil_03/_ato2004-2006/2005/decreto/d5598.htm.

Dias, M. S. L., Bulgacov, Y. L. M., \& Camargo, D. (2007). A vivência do desemprego por jovens aprendizes. Psicologia Argumento, 25 (51), 351-360.

Freitas, M. F. Q., \& Oliveira, L. M. P. (2012). Juventude e educação profissionalizante: dimensões psicossociais do programa jovem aprendiz. Psicologia em Pesquisa, 6(2), 111-120.

Frigotto, G. (2004). Juventude, trabalho e educação no Brasil: perplexidades, desafios e perspectivas. In: Novaes, R.; \& Vannuchi, P. (Orgs), Juventude e sociedade: trabalho, educação, cultura e participação (pp. 180-216). São Paulo: Editora Fundação Perseu Abramo.

Foucault, M. (1971). A ordem do discurso. São Paulo, Edições Loyola.

Guimarães, R. M., \& Romanelli, G. (2002). A inserção de adolescentes no mercado de trabalho através de uma ONG. Psicologia em Estudo, 7 (2), 117-126.

Guirado, M. (1995). Psicanálise e análise do discurso: matrizes institucionais do sujeito psíquico. São Paulo, Summus.

Guirado, M. (1997). Vértices da pesquisa em psicologia clínica. Psicologia USP, 8 (1), 143155.

Guirado, M., \& Lerner, R. (Orgs). (2007). Psicologia, pesquisa e clínica: por uma análise institucional do discurso. São Paulo: Annablume.

Guirado, M. (2010). A análise institucional do discurso como analítica da subjetividade. São Paulo: Annablume.

Lei no 10.097, de 19 dezembro de 2000. (2000, 20 de dezembro). Altera dispositivos da Consolidação das Leis do Trabalho. Brasília, DF: Presidência da República: Casa Civil. Subchefia para Assuntos Jurídicos. Recuperado em 22, novembro, 2015, de http://www.planalto.gov.br/ccivil_03/LEIS/L10097.htm.

Macêdo, O. J. V., Alberto, M. F. P., \& Araujo, A. J. S. (2012). Formação profissional e futuro: expectativas dos adolescentes aprendizes. Estudos de Psicologia, 29(supl), 779s$787 \mathrm{~s}$.

Mandelli, M. T., Soares, D. H. P., \& Lisboa, M. D. (2011). Juventude e projeto de vida: novas perspectivas em orientação profissional. Arquivos Brasileiros de Psicologia, 63 (no.spe), 1-104.

Oliveira, B. R. G., \& Robazzi, M. L. C. C. (2001). 0 trabalho na vida dos adolescentes: alguns fatores determinantes para o trabalho precoce. Revista Latino-Americana de Enfermagem, $9(3), 83-89$. 
Oliveira, D. C., Sá, C. P., Fischer, F. M., Martins, I. S., \& Teixeira, L. R. (2001). Futuro e liberdade: o trabalho e a instituição escolar nas representações sociais de adolescente. Estudos de Psicologia, 6 (2), 245-258.

Pan, M. A. G. S., Rossler, J. H., Ferrarini, N. L., Valore, L. A., \& Oliveira, S. N. (2011). Subjetividade: um diálogo interdisciplinar. Revista Interação em Psicologia, 15 (n.esp), p. 113.

Pineda, D. (2012). Acolhimento institucional e modos de subjetivação. Dissertação de Mestrado, Programa de Pós-Graduação em Psicologia, Universidade de São Paulo, São Paulo.

Pochmann, M. (2007). A batalha pelo primeiro emprego: a situação e as perspectivas do jovem no mercado de trabalho brasileiro. São Paulo: Publisher.

Portaria no 723, de 23 abril de 2012 (2012, 24 de abril). Cria normas de avaliação de competência relativas à verificação da aptidão da entidade para ministrar programas de formação técnico-profissional que permitam a inclusão de aprendizes no mercado de trabalho. Brasília, DF: Ministério do Trabalho e Emprego.

Raitz, T. R; \& Petters, L. C. F. (2008). Novos desafios dos jovens na atualidade: trabalho, educação e família. Revista Psicologia e Sociedade, 20 (3), 408-416.

Sarriera, J. C., Silva, M. A., Kabbas, C. P., \& Lópes, V. B. (2001) Formação da identidade ocupacional em adolescentes. Estudos de Psicologia, 6 (1), 27-32.

Silva, R. D. M., \& Trindade, Z. A. (2013). Adolescentes aprendizes: aspectos da inserção profissional e mudanças na percepção de si. Revista Brasileira de Orientação Profissional, 14 (1), 73-86.

Sposito, M. P. (2005). Algumas reflexões e muitas indagações sobre as relações juventude escola no Brasil. In: Abramo H., \& Branco, P.P.M. (Org.), Retratos da juventude brasileira: análises de uma pesquisa nacional (pp. 87-128). São Paulo: Instituto Cidadania, Fundação Perseu Abramo.

Valore, L. A. (2007). Dos modos de subjetivação em Foucault ao sujeito psíquico da análise institucional do discurso: algumas articulações. In: Guirado, M., \& Lerner, R. (Orgs). Psicologia, pesquisa e clínica: por uma análise institucional do discurso (pp. 223-244). São Paulo: Ed. Annablume.

Recebido / Received: 26/11/2015

Aprovado / Approved: 10/10/2016 